3. Hoag, G.N. Renal carcinoma and vasculitis: report of two cases. J Surg Oncol 1987, 35: 35-38.

4. Chisholm, G.D. \& Roy, R.R. The systemic effects of malignant renal tumours. Br J Urol 1971, 43: 687-700.

5. Mackel, S.E. \& Jordon, R.E. Leukocytoclastic vasculitis. A cutaneous expression of immune complex disease. Arch Dermatol 1982, 118: 296-301.

\section{Subclavian vein thrombosis in a patient with Raynaud's disease}

\section{Sir,}

Axillary or subclavian vein thrombosis (ASVT) accounts for $1-2 \%$ of all deep venous thrombosis. There are three general aetiologies of ASVT: (a) spontaneous; (b) catheter-associated; and (c) miscellaneous causative factors, including trauma, tumours, intravenous drugs abuse, and systemic disease. ${ }^{1}$ We would like to report a case of subclavian vein thrombosis complicated with pulmonary embolism in a patient with Raynaud's disease. To our knowledge, there has been no previous report of this clinical association.

A 26 year old woman with a 2 year history of Raynaud's phenomenon presented with gradual swelling of the left arm. There was no history of trauma, strenuous exercise, or superficial thrombophlebitis nor previous deep vein thrombosis. She was not taking birth control pills. Examination showed the left arm was swollen and there were prominent, distended superficial veins; all other systems were normal. Laboratory values including white blood cell count, haemoglobin, platelets, ESR, prothrombin time, partial thromboplastin time, fibrinogen level, SMA-12 and urinalysis were all normal, as well as a chest X-ray. A venogram showed thrombosis of the left subclavian vein with collateral flow. Heparin therapy was started. Some hours after admission, the patient reported sudden onset of pleuritic left-sided chest pain without dyspnoea or haemoptysis. A perfusion lung scan showed segmental defects in the right middle and left lower lobes. A radionuclide venography of the legs was normal. Treatment with heparin was continued, symptoms gradually subsided, and the patient was discharged 8 days later with oral warfarin. During the hospital course, tests for rheumatoid factor, anti-nuclear antibodies, VDRL, cryoglobulins, antibodies to extractable nuclear antigen (ENA), serum electrophoresis, and the cervical spine and mains X-ray films were negative or normal. After stopping warfarin 6 months later, a coagulation study including prothrombin time, partial thromboplastin time, thrombin time, Howell time, fibrinogen, antithrombin III, protein C, plasminogen, tissue thromboplastin inhibition (TTI) test and platelet neutralization procedure (PNP) test, was normal; serum anti-cardiolipin antibodies were negative and a nailfold capillaroscopy was normal.

Raised blood viscosity, enhanced platelet aggregation and abnormalities in coagulation-fibrinolytic activity, have been reported in patients with Raynaud's phenomenon, especially in the secondary form..$^{2-5}$ In view of those abnormalities all leading to a hypercoagulable state, it is tempting to speculate that our patient's subclavian vein thrombosis was associated with her underlying disease, although her basic coagulation study was normal. We await further reports of similar cases, which would strengthen this impression.

\section{Pedro Laguna \\ Miguel-Angel Sánchez \\ Manuel Moya \\ Hospital Puerto de Hierro, Universidad Autónoma, \\ Madrid, Spain.}

\section{References}

1. Becker, D.M., Philbrick, J.T. \& Walker, F.B. Axillary and subclavian venous thrombosis: prognosis and treatment. Arch Intern Med 1991, 151: 1934-1943.

2. Blunt, R.J., George, A.J., Hurlow, R.A., Strachan, C.J.L. \& Stuart, J. Hyperviscosity and thrombotic changes in idiopathic and secondary Raynaud's syndrome. Br J Haematol 1980, 45: $651-658$.

3. Belch, J.J.F., Drury, J., McLaughlin, K., Anderson, J., Lowe, G.O.D. \& Forbes, C.D. Abnormal biochemical and cellular parameters in the blood of patients with Raynaud's phenomenon. Scot Med J 1987, 32: 12-13.

4. Biondi, M.L. \& Marasini, B. Abnormal platelet aggregation in patients with Raynaud's phenomenon. J Clin Pathol 1989, 42: 716-718.

5. Cimminiello, C., Milani, M., Uberti, T., Arpaia, G., Motta, A. \& Bonfardeci, G. t-PA, PAI, and protein C before and after vascular occlusion of the upper limb in patients with Raynaud's phenomenon. Angiology 1991, 42: 231-238.

\section{Acute granulocytopenia in concomitant treatment of clozapine and methimazole}

Sir,

The major agents employed in the chemotherapy of thyrotoxicosis are drugs of the thionamide class. Methimazole is one of the most widely used anti-thyroid agents. Adverse reactions occur in a small percentage of patients taking methimazole. The most significant of these are skin rash, drug fever, and agranulocytosis $(0.1 \%)$. Of these, the last reaction is the most serious and occurs in a fraction of $1 \%$ of the patients. Agranulocytosis, like the other adverse reactions, generally occurs within the first few weeks or months of treatment. It is accompanied by fever and sore throat, and hence, when therapy is begun, the patient should be instructed to discontinue the drug and notify the physician immediately should these symptoms develop. This precaution is more important than the frequent measurement of leucocytes counts, since agranulocytosis may develop within a day or two. ${ }^{1,2}$ A patient with paranoid schizophrenia and methimazole-controlled Graves' disease, with hallucinatory symptomatology unrestrained by typical neuroleptics was switched to clozapine, a neuroleptic that needs weekly blood cell count for its potential to induce agranulocytosis, and suddently developed granulocytopenia.

A 48 year old woman presented a 23 year history of paranoid schizophrenia with auditory hallucinations, anxiety and systematized delusions. In 1990 Graves' disease was diagnosed and methimazole $150 \mathrm{mg}$ per day was started. She was treated in the last years with haloperidol $15 \mathrm{mg}$ per day, anti-cholinergic compounds and lorazepam $5 \mathrm{mg}$ per day. She also entered trials with 
flupenthixol, zu-clopenthixol and perphenazine, but she always developed extremely severe extrapyramidal reactions. All the symptomatology was not satisfactorily controlled by haloperidol. A blood cell count showed no abnormalities. Clozapine was titrated in 5 days to $250 \mathrm{mg}$ a day and on the fifth day the white blood cell count was $2.2 \times 10^{9} / 1$. Clozapine and methimazole were immediately stopped and after 4 weeks the white blood count was again around $4 \times 10^{9} / 1$. After a few weeks she was surgically treated for the Graves' disease, methimazole was stopped and 2 months later the clozapine treatment was restarted, without side effects on the blood cell count.

The review of the available literature showed no previous reports of agranulocytosis with contemporary use of clozapine and methimazole.

Because toxic side effects occur with both clozapine and methimazole, caution should be used when using these agents simultaneously. ${ }^{3,4}$ This case is reported to underline that the combination of clozapine with other drugs that are known to produce blood dyscrasias, however rarely, could enhance the possibility to develop agranulocytosis.
Certainly more research is needed to help clarify the dangerous interaction when using clozapine.

Pier Luigi Rocco

Emergency Psychiatric Service, St Maria General \& University Hospital, Udine, Italy.

\section{References}

1. Haynes, R.C.J. \& Murand, F. Thyroid and antithyroid drugs. In: Goodman, G.A., Goodman, L.S. \& Gilman, A. (eds) The Pharmacological Basis of Therapeutics. Macmillan, New York, 1980, pp. 1397-1419.

2. Cooper, D.S. Antithyroid drugs. $N$ Engl J Med 1984, 311: $1353-1362$.

3. Lieberman, J.A., Johns, C.A. \& Kane, J.M. Clozapineinduced agranucytosis: non-cross reactivity with other psychotropic drugs. J Clin Psychiat 1980, 49: 371-377.

4. Green, A.I. \& Salzman, C. Clozapine: benefits and risks. Hosp Comm Psychiat 1990, 41: 379-382. 